\title{
PENGARUH PROFITABILITAS, FIXED ASSET RATIO, KONTROL KEPEMILIKAN DAN STRUKTUR AKTIVA TERHADAP STRUKTUR MODAL PADA PERUSAHAAN MANUFAKTUR DI INDONESIA
}

\author{
Hasa Nurrohim KP \\ Jurusan Manajemen UPN “Veteran” Yogyakarta
}

\begin{abstract}
The objective of this article is to identify the determinant influencing the capital structure of manufactured enterprises in Jakarta Stock Exchange for the years 2001 - 2005. This study uses ordinary least square regression to test whether capital structure (proxy long term debt/total asset) is impacted by various variables, namely profitability, fixed asset ratio, ownership's control and assets structure.

Empirical results show that manufactured enterprises employ mostly long term liabilities to finance their operations. An ownership's control and profitability also affects the way a manufactured enterprises its operations. Fixed asset ratio and assets structure seems to have no significant impact on the capital structure of Indonesian manufactured enterprises.
\end{abstract}

Keyword: Capital Structure, Profitability, Fixed Asset Ratio, Ownership Control, Assets Structure.

\section{PENDAHULUAN}

Pasar modal Indonesia telah menjadi perhatian banyak pihak, khususnya masyarakat bisnis. Pasar modal merupakan media yang sangat efektif untuk dapat menyalurkan dan menginvestasikan dana yang berdampak produktif dan menguntungkan investor. Melalui kegiatan pasar modal, perusahaan dapat memperoleh dana untuk membiayai kegiatan operasional dan perluasan perusahaan. Dana diperoleh dari sumber intern dan ekstern perusahaan. Dana yang berasal dari sumber ekstern adalah dana yang berasal dari para kreditor dan investor. Dana yang berasal dari kreditor disebut modal asing yang merupakan hutang bagi perusahaan sedangkan dana yang berasal dari investor disebut modal sendiri.

Sehubungan dengan penyajian laporan keuangan kepada pihak ekstern perusahaan (investor dan kreditor), maka setiap perusahaan harus memiliki struktur modal yang baik. Struktur modal adalah pembelanjaan permanen yang mencerminkan pertimbangan atau perbandingan antara utang jangka panjang dengan modal sendiri (Riyanto, 1995). Struktur modal menunjukkan proposi atas penggunaan hutang untuk membiayai investasinya, sehingga dengan mengetahui stuktur modal, investor dapat mengetahui keseimbangan antara risiko dan tingkat pengembalian investasinya. Investor dari perusahaan dengan leverage tinggi akan menuntut return yang tinggi karena semakin bertambahnya risiko finansial yang harus ditanggung investor. Kreditur menghendaki perusahaan melakukan pengungkapan keuangan secara lebih komprehensif untuk memastikan bahwa perusahaan dapat memenuhi kewajibannya dalam mengembalikan pokok pinjaman (principal) dan sekaligus bunga.

Hutang merupakan salah satu alternatif sumber dana bagi perusahaan, dimana penggunaan hutang pada saat tertentu (keadaan ekonomi baik) akan lebih 
menguntungkan perusahaan dibandingkan dengan modal sendiri, karena akan menurunkan biaya modal dan meningkatkan tingkat pengembalian bagi pemegang saham (Return on Equity). Keputusan pendanaan dengan hutang yang tinggi dan tidak diikuti oleh penggunaan yang hati-hati, karena adanya kecenderungan perilaku opportunistik insider, maka biaya keagenan hutang (agency cost of debt) akan semakin tinggi dan akhirnya juga akan merugikan pemegang saham. Dengan berhutang maka manajemen dipaksa untuk mengeluarkan kas untuk membayar pengembalian hutang, sehingga kelebihan keuangan (free cash flow) yang dimiliki perusahaan menjadi berkurang. Untuk itu diperlukan suatu mekanisme monitoring agar perilaku tersebut diatas dapat dihindari dan manajemen dapat bertindak dengan baik dalam mengelola perusahaan, sehingga dapat menaikkan nilai perusahaan.

Keputusan untuk memilih pendanaan perusahaan sering mendatangkan dilema bagi manajer keuangan. Dilema tersebut adalah manajer harus mampu menghimpun dana, baik yang berasal dari dalam perusahaan maupun dari luar perusahaan secara efisien, dalam arti keputusan pendanaan tersebut merupakan keputusan pendanaan yang mampu meminimalkan biaya modal yang harus ditanggung perusahaan. Biaya modal yang timbul dari keputusan pendanaan tersebut merupakan konsekuensi yang langsung timbul dari keputusan yang dilakukan oleh manajer. Keputusan pendanaan yang digunakan secara tidak cermat akan menimbulkan biaya tetap dalam bentuk biaya modal yang tinggi, yang selanjutnya dapat berakibat pada rendahnya profitabilitas perusahaan.

Perusahaan dituntut untuk mempertimbangkan dan menganalisis sumbersumber dana yang ekonomis guna membelanjai kebutuhan-kebutuhan investasi serta kegiatan usahanya. Untuk itu perusahaan mempertimbangkan berbagai variabel yang mempengaruhinya. Beberapa variabel yang mempengaruhi struktur modal perusahaan (Bambang Riyanto; 1995) adalah tingkat bunga, stabilitas dari earning, susunan dari aktiva, kadar risiko dari aktiva, besarnya jumlah modal yang dibutuhkan, keadaan pasar, sifat manajemen, besarnya suatu perusahaan. Sedangkan Weston dan Brigham (1990) mengungkapkan bahwa variabel yang mempengaruhi struktur modal adalah stabilitas penjualan, struktur aktiva, leverage operasi, tingkat pertumbuhan, profitabilitas, pajak, pengendalian, sikap manajemen, kondisi pasar, kondisi internal perusahaan, fleksibilitas keuangan. Ada empat faktor yang dikemukakan dalam penelitian ini sebagai faktor yang mempengaruhi dalam penentuan struktur modal pada suatu perusahaan, yaitu: profitabilitas, fixed asset ratio, kontrol kepemilikan, struktur aktiva.

Beberapa penelitian mengenai struktur modal diangkat oleh Jaelani La Masidonda (2000) meneliti tentang variabelvariabel yang mempengaruhi struktur keuangan dan pengaruh bersama beban bunga, return on assets terhadap rentabilitas modal sendiri, studi pada industri pharmaceuticals yang terdaftar di BEJ. Hasilnya menunjukkan bahwa pertama, variabelvariabel struktur aktiva, pertumbuhan penjualan, ukuran perusahaan, beban pajak dan laba ditahan berpengaruh signifikan terhadap struktur keuangan, namun secara parsial laba ditahan tidak berpengaruh signifikan terhadap struktur keuangan. Kedua, variabel-veriabel struktur keuangan, beban bunga, dan return on assets berpengaruh signifikan terhadap RMS, namun secara parsial hanya ROA yang berpengaruh signifikan terhadap RMS.

Penelitian Nguyen, Tran Dinh Khoi dan Neelakantan Ramachandram (2006) meneliti mengenai struktur modal dan faktor-faktor yang mempengaruhinya pada 
perusahaan ukuran kecil dan sedang di Vietnam. Hasilnya adalah adanya pengaruh pertumbuhan, risiko bisnis, ukuran perusahaan jejaring, hubungan dengan bank terhadap struktur modal. Sedangkan profitabilitas tidak mempunyai pengaruh terhadap profitabilitas.

Penelitian yang dilakukan oleh Sharma, K Anil (2006) melakukan penelitian tentang hubungan struktur modal dengan nilai perusahaan perusahaan manufaktur di India. Hasilnya ditemukan bahwa adanya hubungan dan pengaruh yang signifikan antara struktur modal dengan nilai perusahaan.

Penelitian yang lain, dilakukan oleh Farah Margaretha (2005). Penelitian mengenai struktur modal dan faktor-faktor penentunya dilakukan terhadap perusahaan multinasional di Indonesia. Hasilnya adalah ditemukannya ukuran perusahaan, tipe industri dan kontrol kepemilikan memiliki pengaruh yang signifikan pada pengambilan keputusan struktur modal perusahaan multinasional.

\section{LANDASAN TEORI \\ Teori Struktur Modal Agency theory}

Teori agensi (Horne, 1995) adalah suatu teori yang menjelaskan adanya pertentangan posisi antara manajemen (sebagai agen) dengan pemegang saham (sebagai pemilik). Para pemegang saham berharap agar agen akan bertindak atas kepentingan mereka sehingga perusahaan dapat meningkat nilainya, sekaligus memberikan keuntungan kepada pemegang saham. Untuk melakukan fungsinya dengan baik, maka manajemen harus diberikan insentif yang memadi, dan juga sekaligus pengawasan yang baik. Pengawasan dapat dilakukan melalui cara-cara seperti pengikatan agen, pemeriksaan laporan keuangan, dan pembatasan terhadap keputusan yang dapat diambil manajemen. Kegiatan pengawasan tentu saja membutuhkan biaya. Biaya ini yang disebut dengan biaya agensi. Biaya yang timbul pasti merupakan tanggungan pemegang saham.

\section{Pecking order theory}

Menurut Myer (1984) dalam Husnan (1996), pecking order theory menyatakan bahwa:

a. Perusahaan menyukai internal financing (pendanaan dari hasil operasi perusahaan, yang berwujud laba ditahan).

b. Apabila dana dari luar (external financing) diperlukan maka perusahaan akan menerbitkan sekuritas yang paling aman terlebih dahulu, yaitu: dimulai dengan menerbitkan obligasi, kemudian diikuti oleh sekuritas yang berkarakteristik opsi (seperti obligasi konversi), baru kemudian apabila masih belum mencukupi akan menerbitkan saham baru.

Sesuai dengan teori ini, tidak ada suatu target debt to equity ratio, karena ada dua jenis modal sendiri, yaitu internal dan eksternal. Perusahaan lebih menyukai penggunaan dana dari modal internal yakni dana yang berasal dari aliran kas, laba ditahan dan depresiasi. Urutan penggunaan sumber pendanaan dengan mengacu pada pecking order theory adalah internal fund (dana internal), debt (hutang) dan equity (modal sendiri).

Dana internal lebih disukai dari dana eksternal karena dana internal memungkinkan perusahaan untuk tidak perlu "membuka diri lagi" dari sorotan pemodal luar. Kalau bisa memperoleh sumber dana yang diperlukan tanpa memperoleh "sorotan dan publisitas publik" sebagai akibat penerbitan saham baru.

Dana eksternal lebih disukai dalam bentuk hutang daripada modal sendiri karena dua alasan (Husnan; 1996), yaitu:

a. Pertimbangan biaya emisi.

Biaya emisi obligasi lebih murah dari biaya saham baru. Hal ini disebabkan 
karena penerbitan saham baru akan menurunkan harga saham lama.

b. Manajer khawatir kalau penerbitan saham baru akan ditafsirkan sebagai kabar buruk (Bad News) oleh para pemodal dan membuat harga saham akan turun. Hal ini disebabkan antara lain oleh kemungkinan adanya asimetrik antara pihak manajemen dengan pihak pemodal.

\section{Trade off theory}

Merupakan model struktur modal yang mempunyai asumsi bahwa struktur modal perusahaan merupakan keseimbangan antara keuntungan penggunaan hutang dengan biaya financial distress (kesulitan keuangan) dan agency cost (biaya keagenan). Dari model ini dapat dinyatakan bahwa perusahaan yang tidak menggunakan pinjaman sama sekali dan perusahaan yang menggunakan pembiayaan investasinya dengan pinjaman seluruhnya adalah buruk. Keputusan terbaik adalah keputusan yang moderat dengan mempertimbangkan kedua instrument pembiayaan. Trade off theory merupakan model yang didasarkan pada trade off antara keuntungan dengan kerugian penggunaan hutang. Trade off tersebut dipengaruhi oleh beberapa variabel. Umumnya oleh keuntungan pajak dari penggunaan hutang, risiko financial distress dan penggunaan biaya agensi. Berdasarkan realita yang berasal dari hutang dalam jumlah yang besar, penggunaan modal sendiri mempunyai manfaat dan kerugian bagi perusahaan. Menurut Brigham (2001), hutang mempunyai keuntungan pada:

a. Biaya bunga yang mempengaruhi penghasilan kena pajak, sehingga hutang menjadi lebih rendah.

b. Kreditur hanya mendapatkan biaya bunga yang bersifat relatif tetap, kelebihan keuntungan akan menjadi klaim bagi pemilik perusahaan.

\section{Struktur modal yang optimum}

Menurut Bambang Riyanto (1995), struktur modal yang optimum adalah struktur modal yang dapat meminimumkan biaya penggunaan modal rata-rata (average cost of capital). Oleh karena itu, manajemen dalam menetapkan struktur modal tidak bersifat kaku (dengan satu patokan) tetapi disesuaikan dengan keadaan perusahaan. Para eksekutif keuangan umunya menyatakan struktur modal yang optimum dalam rentan tertentu, misalnya 40 sampai 50 persen dari hutang.

\section{Faktor-faktor yang mempengaruhi struktur modal}

Menurut Bambang Riyanto (1995) ada beberapa faktor yang mempengaruhi struktur modal yaitu, tingkat bunga, stabilitas earning, susunan aktiva, kadar risiko aktiva, besarnya jumlah modal yang dibutuhkan, keadaan pasar modal, sifat manajemen dan besarnya suatu perusahaan.

Sedangkan pendapat lain, Weston and Brigham (1994) mengemukakan faktorfaktor yang mempengaruhi struktur modal adalah stabilitas penjualan, struktur aktiva leverage operasi, tingkat pertumbuhan, profitabilitas, pajak, pengendalian, sikap manajemen, rating agency, kondisi pasar, kondisi internal perusahaan, dan fleksibilitas keuangan.

Yang terakhir, menurut Farah Margaretha (2005), perusahaan secara umum mempertimbangan beberapa faktor ketika membuat keputusan mengenai struktur modal. Faktor-faktor tersebut adalah ukuran perusahaan (Firm Size), tipe industri (Industry Type), dan kontrol kepemilikan (Ownership Control).

Berdasarkan beberapa teori dan temuan oleh peneliti terdahulu maka penelitian ini mengambil beberapa faktor yang mempengaruhi struktur modal, yaitu profitabilitas, fixed asset ratio, kontrol kepemilikan, dan struktur aktiva. 


\section{METODE PENELITIAN}

Populasi yang digunakan dalam penelitian ini adalah perusahaan yang termasuk dalam perusahaan manufaktur di Indonesia yang terdaftar di Bursa Efek Jakarta, dari tahun 2001 sampai dengan 2005. Jumlah perusahaan manufaktur sebanyak 161 perusahaan, dan sampel yang digunakan dalam penelitian ini adalah perusahaan manufaktur yang berspesifikasi pada sektor industri Consumer Goods sebanyak 21 perusahaan. Pemilihan sampel diambil secara non random sampling, yaitu purposive sampling. Adapun kriteria yang digunakan dalam memilih sampel penelitian adalah sebagai berikut:

a. Perusahaan tersebut memiliki laporan keuangan tahunan periode 2001 sampai tahun 2005.

b. Perusahaan yang mempunyai laba berturut-turut selama lima tahun dari tahun 2001 sampai tahun 2005.

Analisis data dilakukan secara simultan maupun parsial dengan model sebagai berikut:

$$
\mathbf{Y}=\mathbf{a}+\mathbf{b}_{1} \mathbf{X}_{1}+\mathbf{b}_{2} \mathbf{X}_{2}+\mathbf{b}_{3} \mathbf{X}_{3}+\mathbf{b}_{4} \mathbf{X}_{4}+\mathrm{e}
$$

Dimana:

$$
\begin{array}{ll}
\mathrm{Y} & =\text { Struktur Modal } \\
\mathrm{a} & =\text { Konstanta } \\
\mathrm{b}_{1}-\mathrm{b}_{4} & =\text { Koefisien regresi dari setiap }
\end{array}
$$

$$
\begin{array}{ll}
\mathrm{X}_{1} & =\text { Profitabilitas } \\
\mathrm{X}_{2} & =\text { Fixed asset ratio } \\
\mathrm{X}_{3} & =\text { Kontrol kepemilikan } \\
\mathrm{X}_{4} & =\text { Struktur aktiva } \\
\mathrm{e} & =\text { Error term }
\end{array}
$$

\section{HASIL DAN PEMBAHASAN}

Hasil analisis statistik deskriptif data dari seluruh variabel yang akan dimasukan dalam model penelitian terangkum dalam Tabel 1.

Dari Tabel 1 dapat dijelaskan bahwa besarnya struktur modal dari perusahaan manufaktur adalah 0.30222, yang artinya selama periode penelitian, struktur modal memiliki nilai rata-rata sebesar 0,30222. Sedangkan nilai minimumnya 0 dan nilai maksimumnya 4.66933 dari sampel 21 perusahaan selama tahun 2001 sampai 2005.

Sedangkan variabel Profitabilitas, rata-ratanya adalah 0.12228 yang artinya selama periode penelitian, profitabilitas memiliki nilai rata-rata sebesar 0.12228 . Sedangkan nilai minimumnya 0.00339 dan nilai maksimumnya 0.40081 dari sampel 21 perusahaan selama tahun 2001 sampai 2005. Begitu juga untuk variabel yang lain.

Adapun analisis untuk pengujian hipotes terangkum dalam Tabel 2.

Tabel 1: Deskriptif Statistik

\begin{tabular}{lrrrrr}
\hline & N & \multicolumn{1}{c}{ Minimum } & \multicolumn{1}{c}{ Maksimum } & \multicolumn{1}{c}{ Mean } & \multicolumn{1}{c}{ Std Deviation } \\
\hline Struktur Modal & 105 & .00000 & 4.66933 & .30222 & .56225 \\
Profitabilitas & 105 & .00339 & .40081 & .12228 & .08956 \\
Fixed Asset Ratio & 105 & .09097 & .83999 & .38242 & .18346 \\
Kontrol Kepemilikan & 105 & .21400 & .98590 & .74269 & .18016 \\
Struktur Aktiva & 105 & .19000 & 8.7200 & 2.00920 & 1.41866 \\
\hline
\end{tabular}

Sumber: Data Diolah 
SIIERHI Vol. 10 No. 1, JANUARI 2008: 11 - 18

Tabel 2: Hasil Analisis Regresi

\begin{tabular}{|c|c|c|c|c|c|c|}
\hline \multirow[t]{2}{*}{ Variabel } & \multicolumn{2}{|c|}{$\begin{array}{c}\text { Unstandardized } \\
\text { Coefficient }\end{array}$} & \multirow{2}{*}{$\begin{array}{c}\begin{array}{c}\text { Unstandardized } \\
\text { Coefficient }\end{array} \\
\text { Beta }\end{array}$} & \multirow[t]{2}{*}{ t-hitung } & \multirow[t]{2}{*}{ sig } & \multirow[t]{2}{*}{ Keterangan } \\
\hline & Koefisien Reg & Std Error & & & & \\
\hline Konstanta & 1,514 & 0.401 & & 3,775 & 0,000 & \\
\hline Profitabiltas & $-1,436$ & 0,682 & $-0,2290$ & $-2,105$ & 0,038 & Sig \\
\hline Fixed Asset Ratio & $-0,698$ & 0,538 & $-0,2280$ & $-1,299$ & 0,197 & Tidak sig \\
\hline Kontrol Kepemilikan & $-0,784$ & 0,301 & $-0,0251$ & $-2,605$ & 0,011 & Sig \\
\hline Struktur Aktiva & $-0,093$ & 0,069 & $-0,2350$ & $-1,345$ & 0,182 & Tidak sig \\
\hline R Square & 0,176 & & & & & \\
\hline Adjusted R Square & 0,143 & & & & & \\
\hline $\mathrm{F}$ & 5,001 & & & & & \\
\hline Sig & 0,001 & & & & & \\
\hline
\end{tabular}

Sumber: Data Diolah

Dari hasil di atas maka model penelitian ini dapat ditulisnya sebagai berikut:

$$
\begin{aligned}
\mathrm{Y}= & 1,514-1,436 \mathrm{X}_{1}-0,698 \mathrm{X}_{2}-0,784 \\
& \mathrm{X}_{3}-0,093 \mathrm{X}_{4}+\mathrm{e}
\end{aligned}
$$

Berdasarkan Tabel 2 di atas didapat bahwa nilai Adjustd $R$ Squarenya sebesar 0,143, artinya Struktur Modal dipengaruhi oleh Profitabilitas, Fixed Asset Ratio, Kontrol Kepemilikan dan Struktur Aktiva sebesar 14,3\%. Sisanya, sebesar 85,7\% adalah faktor lain di luar faktor yang diteliti. Nilai $\mathrm{F}$ hitung 5,001 dengan probabilitas sebesar 0,001, menunjukkan bahwa Profitabilitas, Fixed Asset Ratio, Kontrol Kepemilikan dan Struktur Aktiva secara bersama-sama mempunyai pengaruh secara signifikan terhadap Struktur Modal pada Perusahaan Manufaktur di Indonesia.

Variabel Profitabilitas menunjukkan nilai t-hitung sebesar -2,105 dengan probabilitas tingkat kesalahan t-hitung sebesar 0,038. Profitabilitas secara parsial mempunyai pengaruh yang signifikan terhadap Struktur Modal. Dengan nilai koefisien sebesar -1,436 maka Profitabilitas mempunyai pengaruh yang negatif (tidak searah) artinya jika Profitabilitas naik (turun) maka Struktur Modal akan turun (naik).

Demikian juga dengan Kontrol Kepemilikan, nilai t-hitung sebesar -2,605 dengan probabilitas 0,011 kontrol kepe- milikan secara parsial mempunyai pengaruh yang signifikan terhadap Struktur Modal. Dengan nilai koefisien sebesar $-0,784$ maka Kontrol Kepemilikan mempunyai pengaruh yang negatif (tidak searah) artinya jika Kontrol Kepemilikan naik (turun) maka Struktur Modal akan turun (naik). Sedangkan variabel yang lain, yaitu Fixed Asset Ratio dan Struktur Aktiva mempunyai nilai thitung $-1,299$ dan $-1,345$ dengan probabilitas sebesar $19,7 \%$ dan $18,2 \%$. Kedua variabel ini secara parsial tidak mempunyai pengaruh terhadap Struktur Modal.

Dari dua variabel yang signifikan diatas maka dapat dilihat variabel yang dominan terhadap Struktur Modal, yaitu Profitabilitas. Karena nilai Betanya paling besar, yaitu 0,229 dibanding 0,0251.

\section{SIMPULAN DAN SARAN Simpulan}

Berdasarkan hasil analisis diatas maka dapat disimpulkan bahwa: pertama, secara bersama-sama variabel Profitabilitas, Fixed Asset Ratio, Kontrol Kepemilikan, Struktur Aktiva berpengaruh signifikan terhadap Struktur Modal. Kedua, Secara parsial/individual hanya Profitabilitas dan Kontrol Kepemilikan yang berpengaruh secara signifikan. sedangkan variabel yang lain, yaitu Fixed Asset Ratio dan Struktur Aktiva tidak berpengaruh signifikan ter- 
hadap Struktur Modal. Ketiga, dari kedua variabel yang signifikan, yaitu Profitabilitas dan Kontrol Kepemilikan, maka Profitabilitas adalah yang paling dominan pengaruhnya terhadap Struktur Modal.

\section{Saran}

Untuk penelitian lebih lanjut sangat faktor independennya sesuai dengan beberapa teori yang sudah diungkapkan. Kedua, untuk sektor industrinya bisa diperluas sesuai dengan data yang ada di Bursa Efek Jakarta. Karena bisa dilihat apakah seluruh perusahaan mempunyai Struktur Modal yang baik atau tidak.

disarankan untuk, pertama menambah

\section{DAFTAR PUSTAKA}

Algifari. (1997). Analisis Regresi (Teori Kasus dan Solusi), Edisi Pertama, Yogyakarta: BPFE.

Arif, Sritua. (1993). Metodologi Penelitian Ekonomi, Cetakan Pertama, Jakarta: Penerbit Universitas Indonesia.

Brigham, F Eugene and Joel F Houston. (2001). Manajemen Keuangan, Edisi Kedelapan, Jakarta: Erlangga.

Gujarati, Damodar. (1999). Ekonometrika Pengantar, Jakarta: Erlangga.

Horne, Van, C. J. (1995). Financial Manajement and Policy, Tenth Edition, New Jersey: Prentice Hall, Internasional Edition.

Husnan, Suad. (1994). Dasar-dasar Manajemen Keuangan, unit Penerbit dan Pencatakan (UPP)-AMP, YKPN, Yogyakarta.

Husnan, Suad. (1996). Manajemen Keuangan Teori Dan Penerapan (Keputusan Jangka Panjang), Edisi Keempat, Buku Pertama, Yogyakarta: BPFE UGM.

Insttitute Foe Economic and Financial Research. (2001-2005). Indonesian Capital Market Directory 2001-2005, Jakarta: Penerbit ECFIN.

Jaelani, La Masidonda. (2000). "Analisis Variabel-variabel Yang Mempengaruhi Struktur Keuangan Dan Pengaruhnya Bersama Beban Bunga, Return On Assets Terhadap Rentabilitas Modal Sendiri”. Tesis, Program Pascasarjana, Universitas Brawijaya Malang.

Lukman, Syamsudin. (1998). Manajemen Keuangan Perusahaan Konsep Aplikasi Dalam Perencanaan, Pengawasan dan Pengambilan Keputusan, Edisi Baru, Cetakan Keempat, Jakarta: Penerbit Raja Grafindu Persada.

Napa, I.A. dan Mulyadi, P.S, (1996). Keputusan-Keputusan Keuangan Perusahaan (Teori dan Hasil Pengujian Empirik), Edisi Kedua, Yogyakarta: Liberty.

Nguyen, Tran Dinh Khoi and Neelakantan Ramachandran. (2006). "Capital Structure in Small and Medium-Sized Enterprises The Case of Vietnam". Asean Economic Bulletin. Academic Research Library.

Riyanto, Bambang. (1995). Dasar-dasar Pembelanjaan Perusahaan, Edisi Keempat Cetakan Pertama, Yogyakarta: BPFE. 
SIIERHI Vol. 10 No. 1, JANUARI 2008: 11 - 18

Sabardi, Agus. (1994). Manajemen Keuangan, Jilid Dua, Edisi Pertama, Cetakan Pertama, Yogyakarta: UPP AMP YKPN.

Sharma, K Anil. (2006). "Financial Leverage and Firms Value A Study of Capital Structure of Selected Manufacturing Sector Firms in India". The Business Review, Cambridge.

Sugiyono. (1999). Metode Penelitian Bisnis, Cetakan Pertama, Bandung: CV. Alfabeta.

Sutrisno. (2000). Manajemen Keuangan Teori Konsep dan Aplikasi, Edisi Pertama, Yogyakarta: Penerbit Ekonisia FE UII.

Weston, J. F. dan Brigham, U. F. (1994). Dasar-Dasar Manajemen Keuangan, Edisi Ketujuh, Jilid Dua, Jakarta: Penerbit Erlangga.

Weston, J. F. dan Copland, T. E. (1997). Manajemen Keuangan, Edisi Sembilan, Jakarta: Penerbit Bina Rupa Aksara. 